\title{
Local treatment for newly diagnosed low prostate-specific antigen, high Gleason score prostate cancer
}

\author{
Shuai Liu', Xiaoying Wang', Guangchen Zhou ${ }^{3}$ \\ ${ }^{1}$ Department of Burns and Plastic Surgery, The Affiliated Hospital of Yangzhou University, Yangzhou University, Yangzhou, China; ${ }^{2}$ Department \\ of Anesthesiology, Subei People's Hospital of Jiangsu Province (Clinical Medical College, Yangzhou University), Yangzhou, China; ${ }^{3}$ Department of \\ Urology, Subei People's Hospital of Jiangsu Province (Clinical Medical College, Yangzhou University), Yangzhou, China \\ Correspondence to: Guangchen Zhou. Department of Urology, Subei People's Hospital of Jiangsu Province (Clinical Medical College, Yangzhou \\ University), Yangzhou, China. Email: guangchenzhou1@163.com. \\ Response to: Guo B, Liu M. Comparative effectiveness of local treatment for low prostate-specific antigen, high Gleason score prostate cancer. Ann \\ Palliat Med 2020. doi: 10.21037/apm-20-1497
}

Submitted Aug 25, 2020. Accepted for publication Sep 25, 2020.

doi: 10.21037/apm-2020-08

View this article at: http://dx.doi.org/10.21037/apm-2020-08

We thank Dr. Guo and his group for their points on our study in Annals of Palliative Medicine. We hereby take the opportunity to address some issues.

The Surveillance Epidemiology and End Results (SEER) database includes 18 cancer registries that cover $28 \%$ of the U.S. population. Using the SEER database, our study has two major clinical implications. First, our results suggest that, for patients with low prostate-specific antigen (PSA) values and Gleason score $8-10$ prostate cancer $(\mathrm{PCa})$, local treatment (LT) results in higher survival compared with no local treatment (NLT). Second, our findings suggest that, in the area of LT, radical prostatectomy (RP) provided the most benefit relative to radiotherapy (RT).

While the SEER database is a powerful source, there are some limitations in our retrospective analysis. SEER does not contain information on androgen-deprivation treatment (ADT) or hemoglobin concentration (1), which may influence the prognosis of patients.

Furthermore, the current treatment strategies for localized PC mainly concentrating RP or RT, so there are significant differences between the LT group and the NLT group in terms of the number of patients, age, Gleason score and other baseline data. The baseline data of patients in RP and RT group were also quite different. Physician referrals and patient selection are inherent limitations of retrospective analysis. To account for this limitation, we used the propensity score matching (PSM) to reduce the differences between groups and make the results comparable.

To address the inherent limitations of a database analysis, further Randomized Controlled Trial is warranted to identify the most effective treatments for patients diagnosed with low-PSA values and Gleason score 8-10 PCa.

Indeed, multiple primary tumors have an impact on patient outcomes. We selected PCa as the first primary tumor. We used SEER, which contains information on cause of death, so we calculated CSS to analyze the difference in prostate cancer death among patients with different treatment regimens.

In our study, the treatment of RP was included only in those who received RP, but adjuvant $\mathrm{RT}$ was not included.

\section{Acknowledgments}

Funding: Supported by the Jiangsu Province Medical and Health research project (No. H2017060).

\section{Footnote}

Provenance and Peer Review: This article was commissioned by the editorial office, Annals of Palliative Medicine. The article did not undergo external peer review.

Conflicts of Interest: All authors have completed the ICMJE uniform disclosure form (available at http://dx.doi. org/10.21037/apm-2020-08). The authors have no conflicts 
of interest to declare.

Ethical Statement: The authors are accountable for all aspects of the work in ensuring that questions related to the accuracy or integrity of any part of the work are appropriately investigated and resolved.

Open Access Statement: This is an Open Access article distributed in accordance with the Creative Commons Attribution-NonCommercial-NoDerivs 4.0 International License (CC BY-NC-ND 4.0), which permits the noncommercial replication and distribution of the article with the strict proviso that no changes or edits are made and the original work is properly cited (including links to both the formal publication through the relevant DOI and the license). See: https://creativecommons.org/licenses/by-nc-nd/4.0/.

\section{References}

1. Ebbinge M, Berglund A, Varenhorst E, et al. Clinical and prognostic significance of changes in haemoglobin concentration during 1 year of androgen-deprivation therapy for hormone-naïve bone-metastatic prostate cancer. BJU Int 2018;122:583-91.
Cite this article as: Liu S, Wang X, Zhou G. Local treatment for newly diagnosed low prostate-specific antigen, high Gleason score prostate cancer. Ann Palliat Med 2020;9(6):4416-4417. doi: 10.21037/apm-2020-08 